\title{
Mulheres, Política e Mídia: algumas \\ INCURSÕES EM TORNO DA REPRESENTAÇÃO sociocultural de Dilma RoussefF
}

\section{(Women, Politics and Media: some investigations around the sociocultural representation of Dilma Rousseff)}

\author{
Maria Carmen Aires Gomes (UFV) \\ Leila Barbara (PUC-SP)
}

\begin{abstract}
Based on research in Systemic Functional Linguistics (SFL) this paper studies the representation of the social actor Dilma Rousseff, when she was Minister of "casa Civil" of the Brazilian Government and was a pre-candidate to the presidency of the country. The data are taken from the on line version of the weekly magazines of general information Veja, Época e IstoÉ. The purpose of the paper is to discuss the magazines' representation of that social actor, based on Theo van Leenwen's $(1996,1997,2008)$ socio-semantic inventory.
\end{abstract}

Key-words: Systemic Functional Linguistics; Representation of Social Actors; Media; Politics.

Resumo: Tomando por base estudos desenvolvidos na Linguística Sistêmico-Funcional $(L S F)$, neste trabalho, investigamos a representação do ator social da então Ministra da Casa Civil, Dilma Rousseff, em revistas semanais brasileiras de informação geral (Veja, Época e Istoé), em sua versão on line, com o objetivo de discutir a forma como essas revistas representam a referida atora social, apoiando, principalmente, no inventário sócio-semântico proposto por Theo van Leemwen (1996, 1997, 2008).

Palavras-chave: Linguística Sistêmico-Funcional; Teoria da Representação dos Atores Sociais; Mídia; Política.

\section{INTRODUÇãO}

A mídia tem papel fundamental na produção, sustentação e transformação de representações das mais variadas realidades socioculturais e, quando se trata do tema política, isso incide nas ações dos políticos. Tais

D.E.L.T.A., 27:2, $2011(311-335)$ 
representações influenciam a formação da opinião pública em diferentes circunstâncias, mas também os próprios eventos e ações da esfera política, inclusive os processos eleitorais. Podemos, assim, dizer que a mídia participa ativamente desse complexo cenário, em que vários eleitores, políticos, instituições e/ou a própria mídia fazem escolhas textuais e linguísticas de forma a ajudarem na transformação, manutenção ou contestação de discursos.

Nesse sentido, vários aspectos particulares do mundo podem ser representados de diferentes formas, uma vez que são instanciados em diferentes discursos. Assim como diferentes relações sociais, instituições e construções identitárias estarão vinculadas a tais construções, levando à compreensão de que discursos não só representam o mundo, como também projetam imaginários, mudanças e geram ações.

No âmbito dos Estudos Culturais, a representação é compreendida como um sistema linguístico e sociocultural vinculado às relações de poder. Segundo Woodward (2009: 17), "é por meio dos significados produzidos pelas representações que damos sentido à nossa experiência e àquilo que somos". Nesse sentido, de alguma forma, um dado aspecto do mundo pode ser representado de diferentes formas em um discurso, texto ou gênero produzido por certa instituição ou por instituições semelhantes ou diferentes, de modo que as distintas formas de representação estão sujeitas a escolhas linguísticas que serão realizadas em construções discursivas, instanciadas nas mais diversas práticas sociais.

Silva (2000: 91), discutindo acerca da noção de representação, afirma que esta "é como qualquer sistema de significação uma forma de atribuição de sentido. Como tal, a representação é um sistema linguístico e cultural: arbitrário, indeterminado e estreitamente ligado a relações de poder". O autor assume ainda que "é por meio da representação que por assim dizer a identidade e a diferença passam a existir. Representar significa neste caso dizer: 'essa é a identidade', 'a identidade é isso'”.

Para van Leeuwen (2008), no âmbito dos estudos discursivos críticos, a representação é uma forma de recontextualização de práticas sociais realizadas em eventos sociais, baseadas naquilo que se diz/faz/representa em contextos socioculturais distintos, instanciando realizações diferentes.

Ressalta-se, portanto, o valor potencial da linguagem na manutenção, produção e transformação das representações. O modo de representar se- 
res, coisas e entidades está na representação de aspectos do mundo físico ou mental, por meio de crenças, sentimentos, valores, realizados por meio de escolhas linguísticas instanciadas em variados contextos de situação. $\mathrm{O}$ conceito de escolha, tomado dos estudos sistêmico-funcionais, é de extrema importância para este estudo, uma vez que as escolhas lexicogramaticais realizadas pelos falantes não são aleatórias, mas estão condicionadas ao contexto. Cada escolha realizada e instanciada de um elemento linguístico pode influenciar ou determinar outras escolhas.

A partir dessas considerações, este artigo consiste em investigar, de forma interpretativa, as representações de uma prática social complexa e recontextualizada: a forma pela qual a mídia impressa brasileira representa Dilma Rousseff, então ministra da Casa Civil e pré-candidata à Presidência da República do Brasil, nas eleições de 2010. Busca-se compreender a forma pela qual os participantes que fazem parte dessa prática social incluem Dilma Rousseff em suas falas. A pesquisa em representação de atores sociais (van Leeuwen, 1997) concentra-se na investigação da maneira pela qual os participantes são incluídos ou excluídos em discursos, principalmente os midiáticos.

Na primeira seção, são apresentados alguns princípios básicos que constituem a Teoria da Representação dos Atores Sociais, segundo Theo van Leeuwen (1996, 1997, 2008), para, em seguida, explicitarmos, na seção 2 os percursos metodológicos, e, na seção 3, descrevermos e analisarmos os diferentes modos pelos quais Dilma Rousseff é representada pelas mídias analisadas.

\section{Modos de Representação dos Atores Sociais (RAS)}

A teoria da representação de atores sociais (RAS) desenvolvida por van Leeuwen $(1997,2008)$ propõe um inventário sócio-semântico, por meio de uma rede de sistemas e categorias pan-semióticas para representar indivíduos em textos. A partir desse inventário, Theo van Leeuwen analisa as realizações linguísticas das representações sociais, atentando-se para as relações entre linguagem, cultura e sociedade, utilizando-se para tanto da teoria Linguística Sistêmico-Funcional, que vê a linguagem como um potencial de significados produzidos em contextos de situação e cultura (cf.: Halliday, 1978). 
A RAS é uma das muitas vertentes que tratam da relação entre linguagem, poder e controle. Alinha-se, portanto, aos estudos discursivos críticos que compreendem o discurso como prática social (uma forma de ação, como algo que as pessoas fazem para e com as outras) e como representação de práticas sociais, ou seja, como forma de conhecimento.

Fairclough (2003), no campo dos estudos discursivos críticos, e alinhando-se às idéias de Theo van Leeuwen, entende que há formas diferentes de representar processos e participantes em situações específicas. A mídia, por exemplo, produz discursos aparentemente desinteressados, imparciais, ou mesmo neutros, de forma a naturalizar significados (Wodak, 2004; Fowler, 1991). Nesse viés, Fairclough (1993) aponta que a notícia jornalística, como prática social da imprensa, é um tipo de prática recontextualizada, em que os participantes ali posicionados transformam e/ou recontextualizam os eventos de forma a representá-los a seus leitores. Ao produzir tal processo, os participantes dessa prática social podem rearranjar as relações sociais, reposicionar os papeis sociais de forma a atender aos interesses e propósitos socioculturais.

Theo van Leeuwen $(1997,2008)$ propõe, assim, uma rede de sistema sócio-semântica, constituída por distintos elementos, que "vão desde o nível léxico-gramatical até o nível do discurso, da transitividade, da referência, do grupo nominal, das figuras retóricas, etc." (van Leeuwen, 1997: 216). Tal rede de sistemas tem como ponto de partida dois eixos: Exclusão (há ausência de representação de indivíduos) e Inclusão (presença de indivíduos nos textos).

A partir dessas categorias basilares, outras são constituídas e subdivididas. Dependendo das escolhas linguísticas, os atores sociais podem ser incluídos ou excluídos em seus discursos de diferentes formas. Ora podem ser incluídos por meio de uma generalização (Políticos são audazes.), ora através de nomeação (Dilma é audaz.), ora pela função (A ministra é audaz.), por exemplo. Se optarmos por uma nomeação para representar alguém, estaremos, talvez, valorizando ou destacando o indivíduo sobre os demais; se optarmos pela exclusão do ator social, isso poderá ser uma decisão de tornar o texto mais coeso e não repetir o léxico, mas também poderá ser um apagamento da responsabilidade ou mesmo a exclusão daquele ator naquela prática social. Theo van Leeuwen aponta que a exclusão tem sido uma categoria bastante utilizada nas pesquisas críticas do discurso que buscam investigar como os atores sociais e suas atividades são excluídos em função de práticas hegemônicas de poder. 
A Exclusão realiza-se por Supressão ou Encobrimento. Theo van Leeuwen (1997) aponta dois motivos para se suprimir atores sociais e atividades: quando os leitores já sabem quem é o ator social; ou para bloquear o acesso a uma prática que, se representada detalhadamente, poderia gerar algum tipo de reação ou contestação. Já o encobrimento é a realização parcial da exclusão: o ator é deixado para segundo plano, porque não é importante que se explicite a sua presença ou porque é possível inferi-lo de qualquer outra parte do co-texto.

O inventário da rede que constitui o sistema de Inclusão é bastante complexo. Nesse sistema, o ator social pode ser representado de diversas maneiras e por diferentes papeis. Para van Leeuwen (1997: 186), as representações constituídas nas práticas sociais podem "redistribuir papeis e organizar as relações sociais entre os participantes", de modo que as escolhas feitas refletem, de alguma forma, os interesses e propósitos daqueles que as selecionaram. O fato é que as maneiras escolhidas para representar um ator social e suas atividades podem, por exemplo, construir a imagem de um indivíduo dinâmico ou passivo, personalizado ou impersonalizado, entre outras.

Dessa forma, serão analisados, neste estudo, 4 subsistemas de inclusão ${ }^{1}$. As definições dessas categorias serão apresentadas na seção 3, destinada à análise dos dados.

\section{Procedimentos metodológicos}

Para a organização dos dados com vista à sua melhor visualização para análise, foram utilizadas duas ferramentas do software computacional WordSmith Tools (Scott: versão 5.0), comparando frequências de termos relevantes para a análise, considerando suas ocorrências em contexto, a saber:

- Lista de Palavras (WordList) - que lista as palavras dos textos, por ordem alfabética e por frequência, bem como fornece dados estatísticos.

- Concordanciador (Concord) - que fornece segmentos de texto a partir de uma palavra escolhida pelo pesquisador.

1. Não trataremos do sistema de exclusão porque objetivávamos saber como os veículos midiáticos incluíam a ministra em suas reportagens e notícias. 


\subsection{0 corpus}

Foram analisados 304 textos midiáticos - gêneros jornalísticos informativos e interpretativos: reportagens e notícias (Melo,1992; Beltrão, 1976), coletados no período de 2003 a 2009, em revistas brasileiras semanais de informação geral: Veja, Época e IstoÉ, nas versões on line das revistas, a partir da palavra-chave "Dilma Rousseff".

Para análise, o corpus foi separado em duas fases. Isso se deve ao fato de Dilma Rousseff ter ocupado, nos anos de 2003 a 2009, dois importantes cargos no governo Lula.

- Fase 1 (2003-2006) - Dilma Rousseff foi nomeada Ministra das Minas e Energias e, posteriormente, ocorreu sua transição para o cargo de Ministra da Casa Civil, substituindo José Dirceu, no primeiro mandato do governo Lula.

- Fase 2 (2007-2009) - Dilma Rousseff já atuando como Ministra da Casa Civil, fase dividida em quatro momentos: (a) Casa Civil - Coordenadora PAC, (b) Cirurgia - pré-candidata, (c) Doença - pré-candidata, (d) Candidata à presidência.

A seguir, para cada fase (1 e 2), observando os itens lexicais por ordem de frequência, foram selecionados os seguintes itens para foco da análise: Dilma, Ministra, Ela, Casa Civil, Minas e Energia, Candidata, Mãe do Pac. $\mathrm{Na}$ sequência, levantamos os contextos em que estes ocorreram, por meio da ferramenta Concordance.

Tomando por base o sistema de Inclusão, a análise do corpus evidenciou os seguintes subsistemas selecionados pelas revistas semanais brasileiras impressas, de cunho geral, para representar a participante Dilma Rousseff: Ativação Passivação (Sujeição e Beneficiação), Personalização, Impersonalização (Objetivação e Institucionalização) e Determinação (Associação, Categorização e Nomeação).

A próxima seção traz a análise e discussão de alguns exemplos observados no corpus.

\section{Análise dos Dados}

\subsection{Ativação}

As representações podem atribuir papeis ativos e passivos aos atores sociais, além de realocarem regras e rearranjarem as relações sociais entre 
os participantes (cf.: van Leeuwen, 2008). Isso se deve, principalmente, ao fato de ser por meio da representação que a identidade e a diferença se ligam a sistemas de poder, ou seja, "quem tem o poder de representar tem o poder de definir e determinar", nomear, ativar, apassivar, categorizar e classificar atores e atividades sociais (Da Silva, 1996: 91).

Ao ser ativado, o ator social pode ser representado como um agente, uma construção dinâmica e ativa, cuja realização pode ocorrer por meio das categorias: participação, circunstancialização e possessivação.

Observe-se que, nos exemplos abaixo, a mídia analisada dá a Dilma Rousseff um papel social ativo, realizado por meio de representação dinâmica, gerando ações sociais:

1) O Programa de Aceleração do Crescimento (PAC), dirigido por Dilma, vai receber $R \$$ 7 bilhóes de investimentos a mais do que previa a proposta.

2) De outro, vários ministros liderados pela chefe da Casa Civil, Dilma Rousseff, cobravam mais dinheiro para investimentos.

Nos exemplos 1 e 2, Dilma Rousseff é ativada por meio de circunstâncias preposicionais: Dilma é agente em relação aos processos de "dirigir" e "liderar", ilustrando a participação de Dilma em processos do tipo material, que, nesse caso, produzem ações, execuções, imagens de liderança.

Os exemplos 3 a 5 se assemelham a 1 e 2 quanto ao papel ativado dado à participante Dilma, representada pela função que exerce no Governo - Ministra Chefe da Casa Civil. No entanto, essas ações e dinâmicas são perpassadas por julgamentos, ora de estima social, ora de moralidade, principalmente quando o assunto é a campanha eleitoral de 2010.

3) As andanças de Lula e Dilma Rousseff Brasil afora são movimentos políticos que miram as eleições presidenciais do ano que vem. "Estão testando a Justiça Eleitoral. Não se tinha visto até então a ministra Dilma fiscalizar obras", disse o presidente do Supremo Tribunal Federal, ministro Gilmar Mendes (Veja, 2009).

4) Lula acha que Dilma manda bastante, mas delega, e com isso as coisas funcionam de forma mais adequada do que na gestão de seu antecessor. Além disso, e esse é um dado relevante para quem conhece a personalidade política do presidente, Dilma Rousseff não oferece sombra ao presidente nem ameaça lhe empanar o brilho (Época, 2008).

5) A Ministra não perde agora uma oportunidade para se mostrar ecológica (Época, 2009). 
Observe que, em 3, 4 e 5, as escolhas lexicais apresentam Dilma como agente dos processos materiais "fiscalizar, oferecer, ameaçar e perder".

Em 4, é agente da ação de oferecer algo à Lula/beneficiário: ela não oferece sombra ao presidente e nem o ameaça, ou seja, não constitui perigo ao Presidente. Podemos dizer que a notícia faz um julgamento por estima social, ou seja, sugere que Dilma não tem capacidade política, pois como pode ser possível uma candidata a um cargo eleitoral não apresentar qualquer tipo de ameaça ao outro? No mesmo segmento, Dilma é representada, aos olhos de Lula, como agente dos processos materiais "mandar" e "delegar", novamente uma agência dinâmica que, de alguma forma, sinaliza um baixo potencial político de Dilma, pois, ao representá-la como alguém que manda ou delega, está apenas atribuindo-lhe uma característica de gestora. O texto deixa transparecer que Dilma é uma boa gestora, mas não se caracteriza como uma política hábil.

Nesses segmentos, há ainda outro elemento que representa as ações políticas de Dilma pré-candidata de forma negativa. Há a implicação de que Dilma só age dinamicamente ante um comando do Presidente Lula: "Não se tinha visto até então... fiscalizar obras" e "A Ministra não perde agora uma oportunidade para se mostrar ecológica". Apesar de essas construções representarem Dilma como agente, as avaliações resultam em julgamentos de sanção social por veracidade, pois colocam em dúvida a autenticidade ou honestidade das ações empreendidas por Dilma pré-candidata, por meio, principalmente, da polaridade negativa (não) e da circunstância (agora, até então): "não se tinha visto até então" e "não perde agora", indicando uma mudança de comportamento.

\subsection{Passivação}

Theo van Leeuwen (1997) aponta que os atores sociais podem ser dotados quer de papeis ativos, quer passivos. $\mathrm{Na}$ passivação, o ator social é o paciente, aquele que é submetido a uma ação, cuja realização se dá pela sujeição e beneficiação.

Ao contrário do que aparece acima, em outros momentos, a participante Dilma é representada no corpus de forma apassivada - como em 6 e 7 - pelo agente Lula (sua candidata). Observe que o ex-presidente é 
representado como possuidor da candidata Dilma, sugerindo ser esta de sua propriedade.

6) A verdade é que Lula usa e abusa do dinheiro público para empinar sua candidata (Época, 2009).

7) Lula impulsiona sua candidata com o discurso retrógrado-nacionalista de que só o PT protege o Brasil (Veja, 2009).

\subsubsection{Sujeição}

$\mathrm{Na}$ sujeição, o ator é sujeito/paciente/vítima da ação, enquanto na beneficiação, o beneficiário/beneficiado é aquele a quem os bens são dados, ou o cliente, para quem os serviços são prestados. O participante pode se beneficiar de forma positiva ou negativa de algum objeto.

No exemplo 8, Dilma Rousseff é representada como ator social passivado, tratado como uma entidade que sofre o efeito de alguma ação, uma sujeição: "o câncer linfático apanhou Dilma". Mas observe-se que ela, ao mesmo tempo em que é representada como vítima da doença, é também julgada pelo fato de isso ocorrer em meio a um contexto pré-eleitoral (num momento peculiar de sua candidatura).

8) O câncer linfático apanhou Dilma Rousseff num momento peculiar de sua candidatura ao Planalto (Época, 2009).

Os exemplos 9 e 10 representam Dilma Rousseff como paciente no contexto pré-campanha, enquanto o Presidente Lula é representado como agente da ação. Observe-se, ainda, uma clara sinalização de que Dilma nada conquistará, mas, ao contrário, será paciente de uma ação - não conquistará o cargo de Presidente por suas habilidades e competências, mas será colocada, carregada, pela popularidade do Presidente Lula. Nos exemplos abaixo, o Palácio do Planalto/Lula coloca Dilma no poder, ou seja, ela não o conquista por seus méritos. O tom da notícia é de que Lula será o responsável pela vitória da participante Dilma. A mídia parece sinalizar para uma representação de Dilma como um tipo de marionete.

9) Na quinta-feira 12, o Palácio do Planalto colocou Dilma no centro do palco do anúncio do indice de desmatamento da A mazônia no período entre agosto de 2008 e julho de 2009. O governo fez questão de atribuí-lo a uma operação conjunta entre a Polícia Federal, o Ministério do Meio Ambiente e o do Desenvolvimento Agrário, coordenada por Dilma (Época, 2009). 
10) Lula está usando esse patrimônio (índices de popularidade) para fazer a ministra-chefe da Casa Civil, Dilma Rousseff, sua sucessora (Época, 2009).

\subsubsection{Beneficiação}

Beneficiação é uma das categorias sócio-semânticas propostas por van Leeuwen (1997). O ator social é favorecido ou desfavorecido em relação a alguma ação ou atividade - o beneficiário, em geral, é animado, beneficiado ou prejudicado por algum bem ou serviço; portanto, é uma ação que resulta de algum proveito ou prejuízo, em que o participante recebe vantagens, que podem ser, inclusive, um objeto.

A participante Dilma Rousseff é representada, de forma recorrente, por meio da passivação por beneficiação, principalmente no que se refere ao contexto de campanha eleitoral, tendo o presidente Lula e sua equipe como agentes do benefício.

No exemplo 11, a escolha lexical apresenta Dilma (por ela) como beneficiária da ação verbal de Lula (pediu para que) e do processo material (rezassem): Lula desencadeia uma rede de ações: pede algo/serviço ao eleitor para a Dilma, que se torna beneficiária/cliente desse serviço.

11) Do alto do palanque, reforçou que Dilma é sua candidata e, num gesto bumano, pediu para que rezassem por ela. Tudo previamente pensado. Além de neutralizar as tentaçôes petistas, Lula acredita que Dilma pode se fortalecer politicamente com a doença (Veja, 2009).

De 12 a 14, temos outros exemplos retirados dos dados que representam Dilma como alguém ajudada/apoiada pelo Presidente e sua capacidade de comando. Nesses excertos, Dilma Rousseff é beneficiada por ações realizadas por um agente (Lula), por meio de processos materiais (patrocinar, cacifar) com efeito irônico e crítico. Em 12, com "cacifar", uso metafórico lexical, o texto sugere que Lula pagou para que Dilma entrasse no jogo político. No sentido dicionarizado, o termo cacifar significa "em certos jogos, recolher o cacife (dinheiro pago por todos os jogadores)", porém, no exemplo, podemos dizer que há uma realização metafórica de pagamento, patrocínio.

12) Ao cacifar a ministra Dilma Rousseff, campeã das críticas à política econômica no governo, Lula mostrou que vai continuar o cerco ao ministro da Fazenda, Antônio Palocci, para flexibilizar a estratégia de altos superávits primários (Época, 2005). 
Em 13 e 14, com patrocinar, a implicação é semelhante, pois sugere que Lula faz uso de seu prestígio (tem sido eficaz) para que Dilma seja eleita. Representa Dilma como beneficiária da política de Lula.

13) "Para patrocinar Dilma, Lula tinha de torná-la conbecida. E tem sido eficaz nisso" (Época, 2009).

14) "A ideia de patrocinar uma candidatura feminina alimenta o círculo de assessores de Lula há mais tempo do que se imagina" (Época, 2009).

Nos exemplos 15 e 16, o Presidente Lula aparece como agente desencadeador de um processo de pré-candidatura - como agente, ele tem o controle, a intenção. Ele desencadeia ações favoráveis à candidatura de Dilma Rousseff, que recebe benefícios e, portanto, é afetada pelas intervenções, bens e serviços doados/dados principalmente por Lula. Observe-se que os benefícios, bens, representam a meta: herança bendita e formidáveis indices de aprovação popular.

15) Lula espera transformar parte de sua popularidade recorde, que chega aos $70 \%$, em votos para Dilma. Para receber a berança bendita, porém, a ministra precisa se tornar conbecida (Istoé, 2009).

16) A candidata preferida de Lula à sucessão é a ministra-chefe da Casa Civil, Dilma Rousseff. Ele não tem desperdiçado uma tentativa de deixar claro que quer presenteá-la com seus formidáveis indices de aprovação popular (Época, 2009).

Quando a participante Dilma é representada por beneficiação, o contexto geralmente está vinculado à pré-candidatura da Ministra, e, na maioria das vezes, atribui-se a ela um tom irônico (campeã das críticas, ele não tem desperdiçado, herança bendita, presenteá-la). Esse tom irônico exprime posicionamentos ideológicos, pois, dar algo a alguém, seja por meio de uma herança ou de um presente, não é diferente da ação de comprar ou conquistar algo. Em 15, por exemplo, Dilma se beneficia dos índices de popularidade do Presidente Lula.

Ao representar Dilma como beneficiária da popularidade, das ações e do interesse político do Presidente Lula, a mídia desconsidera-a/deslegitima-a diante da sociedade, tornando-a um objeto de troca política ou mesmo um joguete nas mãos do Presidente e de sua equipe para que ele alcance outros propósitos políticos (retornar em 2014), como em 17: 
17) Dirceu atua nas costuras de bastidores, longe dos olhos da nação, ofício em que é mestre. Ele trabalha como um tecelão, costurando a favor de Dilma uma teia resistente e capilarmente espalhada pelo país, formada por governadores e prefeitos fiéis ao projeto continuísta do PT (Veja, 2009).

No contexto político, o processo material "costurar", realizado metaforicamente, significa buscar alianças, acordos, articulações e conchavos. No excerto 17, Dirceu tece, então, estreitamente as redes, alianças e conchavos em favor de Dilma.

Outra representação da atora em questão, observada em diversas ocorrências, está vinculada ao uso do processo material "aproximar", descrita em $18,19,20$ e 21 . Observe-se que há sempre algo ou alguém que promove a aproximação de Dilma. São os aliados, os empresários, movimentos políticos que a tornam beneficiária da ação.

18) $O$ comando dos $\boldsymbol{R} \$ 503,9$ bilhões do PAC ajuda a aproximar Dilma do empresariado (IstoÉ, 2008).

19) "Encontros com movimentos de negros, sem-teto e mulheres estão na pauta", diz um assessor da ministra. A aproximação de Dilma com o eleitorado feminino é vital para suas pretensões eleitorais (Época, 2009).

20) O ministro das Comunicações, Hélio Costa, já se colocou à disposição para tentar aproximar o PMDB de Dilma. Em troca, quer que a ministra o apóie para o governo de Minas Gerais (Veja, 2008).

21) Foi Araújo, um brizolista, quem aproximou Dilma do PDT, partido em que ela iniciou sua carreira política (Época, 2007).

Ao usar a construção nominalizada "o comando", em posição temática, no exemplo 18, o texto gera um efeito de algo já conhecido, de informação já dada representada pelo artigo definido "o". Isso coloca em proeminência a ação, e não o ator, que é deixado em segundo plano, ofuscando, assim, sua agência e acarretando efeitos ideológicos. No entanto, nesse caso, Dilma é, simultaneamente, agente e paciente: agente da ação de comandar, e beneficiária da ação de se aproximar do empresariado, ou seja, está no comando do PAC, mas, para ser uma gestora eficiente e politicamente aceita, sofre a ação de aproximar-se do empresariado.

Em 19, observa-se que Dilma não age, não se aproxima sozinha de algo ou alguém; ela é beneficiada ou sujeita a ação de outros, ou seja, retira o caráter de ação de Dilma. O uso da metáfora gramatical, nominalização $-A$ 
aproximação de Dilma -, discursivamente falando, é um modo de esconder o enunciador e de conceder ao texto um caráter mais objetivo, neutro e impessoal, procurando dirigir a atenção do leitor apenas para o ato ou processo em si, ou seja, esconde os problemas relativos a essa aproximação: quem está se aproximando, por qual motivo, quem foi o responsável pelo processo de aproximação?

Nesse direcionamento, Chilton e Schaffner (2001) dizem que a nominalização cumpre a função de autolegitimação e vincula-se à estratégia de encobrimento, ou seja, encobre-se uma prática social, um evento ou mesmo um agente.

\subsection{Personalização}

As escolhas lexicogramaticais podem revelar também a forma como os atores sociais podem ser incluídos nos textos. Dessa forma, os atores sociais podem ser representados de forma personalizada [Personalização], por meio de pronomes pessoais, possessivos adjetivos, nomes próprios ou substantivos, com características humanas.

A personalização foi um tipo de representação recorrente neste estudo. Dilma Rousseff foi, na grande maioria das matérias, referida de maneira especificada, ora por nome próprio, ora por pronomes pessoais. A personalização frequentemente confere à Dilma Rousseff notoriedade/destaque pelo fato de ela ocupar um alto cargo político, já que está à frente de uma das pastas mais importantes do governo: a Casa Civil.

No inventário sócio-semântico proposto por van Leeuwen, a personalização se desdobra em algumas subcategorias, que serão descritas a seguir. As escolhas representacionais que personalizam os atores sociais são realizadas por meio de pronomes pessoais ou possessivos, nomes próprios ou substantivos que tenham um tipo de caracterização humana.

Em 22 e 23, o ator social foco deste trabalho aparece pelo primeiro nome e pelo pronome pessoal:

22) Lula parece confiar em Dilma porque ela, ao contrário de José Dirceu, não tem projeto político próprio (Época, 2009).

23) Ela não deseja ser política. Dilma quer só mandar (Veja, 2008). 
Observe que, em 22, a matéria jornalística especifica por meio de nome próprio a atora social (Dilma), deixando explícita a atribuição negativa dada a ela: "não tem projeto político próprio". Vale ressaltar o uso da polaridade negativa realizada com o processo relacional possessivo corroborando a falta de autonomia e habilidade política. Em 23, o pronome pessoal (ela) representa o ator social como uma participante, que tem desejos, volições, por meio dos processos mentais desiderativos "desejar" e "querer", modalizados pela polaridade negativa: "Ela não deseja ser política" significa dizer que ela não quer fazer parte do grupo de políticos.

Esse tipo de personalização pode ser um tipo de estratégia discursiva usada pela imprensa para tornar as ações e atividades do ator social explícitas para a sociedade. Ao especificar, nomear o ator social, a mídia pode estar chamando atenção da sociedade para os fatos que se referem às ações políticas, competências, habilidades dos atores políticos, ora para elogiá-las, ora para denunciá-las.

A atribuição de nomes revela também destaque e valorização. Theo van Leeuwen (1997: 191) aponta que "nos jornais dirigidos à classe média os agentes e especialistas governamentais tendem a ser referidos especificamente. A nomeação, em diversas ocorrências, realiza-se geralmente por meio de nomes próprios: (i) formal, "Dilma Rousseff", (ii) semi formal, "Dilma":

26) "Dilma quer tocar grandes obras, como as duas hidrelétricas no Rio Madeira, em Rondônia, e encara a política ambiental como um obstáculo" (Veja, 2009).

27) "Nos últimos dias, Dilma Rousseff tem discutido o tema com parlamentares e empresários para ajustar suas idéias ao bumor dos investidores estrangeiros" (Veja, 2009).

Nos exemplos 28 a 30, é possível perceber que a nomeação foi realizada de maneira informal, por meio da construção afetiva, da realização de sufixos de diminutivo e aumentativo:

28) "Dilminha, sai fora disso. Saia de cena. (Lula) "Alô, Dilminha? Estamos decolando aqui de Buenos Aires. Liguei só para lhe dar os parabéns". Presidente Lula, em telefonema à ministra Dilma Rousseff, para cumprimentá-la pelo leilão do Rio Madeir (Época, 2009).

29) "Ele me disse que vai trabalhar 24 horas por dia para entregar antes do prazo. Mas é isso, Dilminha, liguei só para lhe dar os parabéns. Tchau!" (Época 2009)

30) É esse o processo que agora busca transformar "Dilmão" - o apelido que a ministra da Casa Civil tem no governo - em "Dilminha" (Veja, 2009). 
Os exemplos 28 e 29 ilustram a nomeação por diminutivo, acentuando valor afetivo, de carinho, delicadeza, uma vez que está sendo usada por Lula (mentor e aliado de Dilma Rousseff), sugerindo que ambos compartilham objetivos, desejos e sentimentos, construindo uma relação simétrica ao contrário do exemplo 30, que, cumprindo papel social midiático, difere daquela construção escolhida pelo Presidente. "Dilmão e Dilminha", em 30, identificam a participante de forma depreciativa e irônica, nos quais há julgamento de estima social. Ao usar o sufixo com valor avaliativo, a matéria jornalística parece reduzir a força político-administrativa de Dilma Rousseff perante os leitores, orientando a construção avaliativa identitária da Ministra.

Outra representação recorrente da atora social é a nomeação por honorificação, ou seja, utilizando títulos: "Se comprovado, o encontro criaria sérios constrangimentos legais à ministra, pré-candidata do PT à Presidência da República".

Observe que, nas construções personalizadas, nos exemplos acima, há uma atribuição ora negativa, ora irônica dirigida à Ministra pela mídia. Dilma é sempre qualificada, com adjetivações e metáforas daquilo que é ou faz, com definições e designações, como por exemplo, a oposição "Dama de Ferro" e "Regina Duarte" (Dilma é comparada à atriz que é conhecida por sua meiguice e simpatia):

31) "Resumindo, com acidez oposicionista, uma impressão de boa parte dos meios políticos, o ex-prefeito do Rio de Janeiro Cesar Maia fez uma advertência: "Se ela ficou conbecida como a dama de ferro e por isso ascendeu, ninguém vai entender agora se quiser virar a Regina Duarte" (Época, 2009).

No exemplo 31, observe que Dilma Rousseff é definida pela prática na qual se engaja (Ministra da Casa Civil) e pelos efeitos que produz, a partir das ações que realiza/executa, responsáveis por torná-la "dama de ferro".

\subsection{Personalização por Determinação por Associação}

Outro tipo de representação observada no corpus foi a determinação por associação, quando o participante se associa a outro para formar um grupo institucional e estável. Os exemplos abaixo ilustram tal representação, muito comum na esfera política, uma vez que explicita possíveis alianças ou mesmo disputas e negociações. 
32) Campos, Lula, Dilma e Geddel: vistoria de obras com direito a show, uísque e cerveja (Veja, 2009).

33) Chances não faltarão para o governo aumentar a associação entre Lula e Dilma (Istoé, 2009).

34) As andanças de Lula e Dilma Rousseff Brasil afora são movimentos políticos que miram as eleiçoes presidenciais do ano que vem (Veja, 2009).

35) O presidente Lula com Dilma em cerimônia em Santa Catarina. Até a semana passada ela era a "mãe do PAC" (Istoé, 2009).

Observe-se que, em 32, "Campos, Lula, Dilma e Geddel" estão associados para formar um grupo que partilha propósitos, atividades, ações e representam uma aliança em relação ao evento: "vistoria de obras com direito a show, uísque e cerveja". A descrição detalhada do evento sugere crítica e ironia, sinalizando para a ideia de que foi uma vistoria mascarada de comício. Em 33 a 35, há ênfase na associação entre Lula e Dilma, sugerindo uma forte parceria, cumplicidade.

Encontramos, ainda, realizações de associação, por meio da construção "com Dilma Rousseff", exemplo de circunstância de acompanbamento:

36) Acham que o tucano, até março, passará a dividir com Dilma Rousseff um peso que ela carregava sozinha: a suspeita de que todos os seus atos no governo sempre ocultam uma motivação eleitoral (Istoé, 2009).

Observamos, também, a ocorrência de um tipo de associação que estamos denominando de associação por fusão, sugerindo um tipo de aliança estável ou parceria comprometida.

37) Em outro trecho, o documento diz que, diante da campanba de Dilma, Serra está "em situação dramaticamente assimétrica: tem menos exposição na mídia nacional, menos mobilidade, menos máquina, menos recursos, menos espaço para se defender e contra-atacar do que Lula/Dilma" (Época, 2009).

38) A peça de resistência será, sem dúvida, a dobradinha Lula-Dilma. Dessa forma, o PT espera conquistar seu maior desafio: transformar a imensa popularidade de Lula em votos para a sua candidata (Veja, 2009).

Observe que, em 37 e 38, Lula e Dilma não estão associados por meio de uma adição (e), ou mesmo por uma circunstância de acompanhamento (com), mas pelo hífen ou barra. Ao usar tais recursos, a mídia liga os dois nomes (Lula e Dilma), produzindo uma palavra composta, por meio do 
traço de união, em 38, por exemplo. Tal escolha rearranja os papeis dos atores sociais de forma a fundi-los.

\subsection{Personalização por Determinação por Categorização}

A determinação se subdivide em Funcionalização, Identificação e Avaliação. A Funcionalização - representação recorrente no corpus - ocorre quando um ator social é referido por meio de um substantivo ou grupo nominal referente a um papel ou atividade institucional.

Os exemplos 39 a 41 funcionalizam Dilma Rousseff por meio dos itens lexicais Ministra, Ministra-chefe da Casa Civil, Chefe da Casa Civil para dar mais legitimidade às ações desenvolvidas por ela:

39) A preocupação dos aliados é saber como a ministra vai lidar com a necessidade de uma maior interferência externa na sua própria campanha (Veja, 2009).

40) Chefe da Casa Civil, Dilma Rousseff comanda o ambicioso programa de investimentos para 2006, que vai da continuação da Ferrovia Norte-Sul à operação para tapar buracos nas estradas (IstoÉ, 2005).

41) Se comprovado, o encontro criaria sérios constrangimentos legais à ministra, précandidata do PT à Presidência da República (Época, 2009).

Somem-se a essas realizações outras funcionalizações com uso de epítetos com valores atitudinais e atributivos bastante irônicos: poderosa ministra, assessora desconhecida.

42) Ele caiu nas graças do presidente e da poderosa ministra da Casa Civil, Dilma Rouseff, pela forma como pilotou a crise do gás com a Bolívia. (Veja, 2008).

44) $A$ assessora desconbecida deixou o ostracismo e se converteu em candidata viável (Veja, 2009).

Dilma Rousseff é afetada por uma avaliação desfavorável, deslegitimadora, principalmente no excerto 44, em que tal representação realiza um discurso que denota uma crítica irônica ao papel institucional de Dilma, observável nas expressões "assessora desconhecida, ostracismo e se converteu". Tais escolhas lexicogramaticais sugerem, ironicamente, que Dilma sai do isolamento político e abraça um novo credo político, que pode tornar Dilma uma candidata viável. Observe que o léxico "viável" está no eixo da possibilidade, ou seja, tal realização pode ser possível, pode ser levada a 
efeito. Portanto, não se trata de uma opinião-convicção, mas uma probabilidade, uma suposição.

A Identificação é uma das sub-categorias da categorização. Theo van Leeuwen (1997) distingue três principais formas de identificar algo ou alguém, a saber: Classificação, Identificação Relacional e Identificação Fúsica. Enquanto na funcionalização, os atores sociais são representados pelo que fazem, na classificação, o foco está no que eles são.

As classificações podem incluir gênero, origem geográfica, riqueza, etnicidade, orientação sexual, entre outras categorias históricas e culturalmente variáveis. Quando classificamos algo ou alguém, podemos representar com doing (fazendo/acontecendo) ou como being (estando ou sendo algo ou alguém).

$\mathrm{Na}$ representação de atores sociais por classificação, registramos a classificação por identificação, a saber:

\section{1 - Classificação por afiliação política e filosófica}

45) A petista participa de um almoço com mulheres para mostrar que não é só um rostinho sisudo (Época, 2009).

46) Militante trotskista na década de 1960, Dilma fez um périplo por todas as religiões e até chorou na festa do Círio de Nazaré (Época, 2003).

Observe-se que, em 45 e 46, as designações "petista e militante trotskista”, usadas para representar Dilma, estão na posição temática, funcionando como ponto de partida para a mensagem, orientando argumentativamente a leitura. Ao representá-la de forma classificatória, sua identidade passa a ser definida e determinada.

\section{2 - Classificação contexto da ditadura}

47) Ex-guerrilheira, a ministra das Minas e Energia descarta falta de energia no governo Lula e promete mudanças (Época, 2003).

48) Foi um ano de duras batalhas para a ex-guerrilheira Dilma Rousseff. A maior de todas, um câncer no sistema linfático, foi enfrentada com dignidade e vencida com bravura. Menos definitivo foi o resultado de seu embate com a ex-secretária da Receita Lina Vieira em torno de um encontro de desdobramentos suspeitos cuja existência ela nega e a ex-secretária reitera (Época, 2009).

49) A ministra-chefe da Casa Civil, a ex-guerrilheira Dilma Rousseff, metralhou seu (Palocci) plano de ajuste fiscal de longo prazo e aumentou o tom de voz contra a equipe econômica que segurava verbas para obras de infra-estrutura (Veja, 2005). 
Os epítetos usados em 47, 48 e 49 salientam a identidade de Dilma Rousseff como ex-guerrilheira e, com isso, o texto diz o que ela é e a que grupo pertence, ou mesmo quem poderiam ser seus aliados, ou seja, quem está incluído e quem está excluído de seu grupo. Essas escolhas classificatórias podem ser interpretadas como um tipo de estratégia discursivo-política das revistas para não permitir que o leitor esqueça o passado revolucionário da candidata à Presidência da República.

Outros exemplos encontrados no corpus são de Identificação por Classificação. Nos exemplos abaixo, o termo "gerentona", com o sufixo avaliativo, sugere crítica, ironia.

50) Aquela de poucos sorrisos, sisudez e pulso tão firme a ponto de provocar distância - sobretudo de seus subordinados. Essas qualidades conferiram veracidade ao título que o presidente Luiz Inácio Lula da Silva queria pregar-lhe, o de "mãe do PAC" ou, como alguns preferem, o de "gerentona" (Veja, 2009).

51) Dilma Vana Rousseffé a ministra-chefe da Casa Civil, a gerentona do governo que o presidente Lula escalou para tocar com mão de ferro o Programa de Aceleração do Crescimento, o PAC (Veja, 2007).

Em 51, por exemplo, o léxico "gerentona" tem uma carga extremamente negativa no contexto, uma vez que busca reforçar o papel social de Dilma como aquele sujeito responsável pelo planejamento e controle da execução dos trabalhos de seus subordinados.

Houve, ainda, a representação por Identificação Relacional. Observe que Dilma Rousseff é classificada com base em suas funções, porém, em alguns momentos, como em outras situações, algumas mencionadas acima, essas representações se constituem em acentos irônicos. Por exemplo, de 52 a 54, há marcas de classificação, por meio do sintagma preposicional pós-modificador. Para Halliday (1994), os classificadores correspondem a informações sobre o que está sendo mencionado, detalhando, seja por adjetivos, advérbios, substantivos ou verbos.

52) $A$ "mãe do PAC" terminou a semana sob a suspeita de ter sido a madrinha de uma engrenagem que pôs na rua informaçoes sigilosas sobre despesas pessoais do ex-presidente (Veja, 2008).

53) A maior entusiasta de um governo intermediário entre Lula $2 D$ e Lula $3 D$ tem sido a ministra Dilma Rousseff. Sondada para encabeçar a chapa desse acordo, topou na hora. Ou seja, se for a candidata de Lula, Dilma compromete-se a ficar um só mandato, caso seja eleita (IstoÉ, 2007).

54) A dama do PAC. No governo, só deu ela (Época, 2008). 
No exemplo 54, percebemos uma construção irônica mais acentuada ao empregar o termo dama, fazendo uma designação honorífica ou respeitosa: dama do PAC no sentido de a rainha do PAC.

Outra representação de destaque no corpus foi a categorização por avaliação, principalmente no Contexto Pré-Eleição.

55) Nos fins de semana, Dilma reserva um dia, às vezes o sábado, às vezes o domingo, para se dedicar integralmente ao treinamento e à preparação da "candidata ideal" (Época, 2009).

56) Entrou em rota de colisão com a ministra-chefe da Casa Civil e virtual candidata à Presidência, Dilma Rousseff, por causa de divergências em torno de exonerações fiscais do programa Minha Casa, Minha Vida, que pretende construir 1 milhão de casas populares (IstoÉ, 2009).

57) O presidente Lula não esconde que Dilma Rousseffé a candidata oficial à sua sucessão e se aproveita de uma omissão legal para torná-la conhecida entre os eleitores (Veja, 2009).

Halliday (1994) lembra que os participantes podem estar acompanhados de epítetos, realizados por adjetivos ou mesmo substantivos, que correspondem, basicamente, às qualidades das entidades. Em português, os epítetos vêm usualmente após a entidade e contribuem para a construção semântica da entidade da qual se fala Dois ou mais adjetivos podem caracterizar as qualidades do referido participante.

58) Uma das principais conselheiras de Lula e candidata informal ao Planalto, a ministra da Casa Civil fala à Época sobre a crise (Época, 2009).

59) Se inicialmente o presidente pôde usar Dilma como uma espécie de candidata-rolha a segurar qualquer tentativa de antecipar o debate da sucessão, agora Lula corre o risco de se ver numa armadilha eleitoral causada pela popularidade estratosférica (Veja, 2009).

60) Nesses encontros são discutidos os temas que serão abordados pela candidata-ministra e como ela deve tratá-los em suas aparições (Veja, 2009).

Encontramos epítetos principalmente nas categorizações avaliativas: tampão, rolba, ideal, de Lula, virtual, boa candidata à vice, construindo, na ótica dos veículos midiáticos analisados, a representação de Dilma-Ministra como um ator coadjuvante na pré-campanha para as eleições 2010, que confirmam a construção de participante/beneficiária principalmente dos benefícios, bens e serviços dados pelo Presidente Lula.

61) Ao procurar dar traços delicados à ministra, a cirurgia é uma forma de ressaltar aquele aspecto que está no centro de sua candidatura - a ideia de lançar uma candidata mulber à Presidência da República (Veja, 2009). 
62) "Bom, ela poderia ser uma boa candidata a vice. Daquelas que a gente esconde na campanha, diz o publicitário Chico Santa Rita" (Época, 2009).

63) Eles argumentam que os efeitos da crise devem reduzir a capacidade que Lula tem de transferir votos a uma candidata sem experiência (Veja, 2008).

64) Dilma Rousseff é vista nos corredores maldosos de Brasília como ministra-tampão, sacrificável numa eventual aliança, caso Lula não consiga governar sem maioria, baseado apenas no espírito PAtriótico do Congresso (Veja, 2003).

Fowler (1993) aponta que as escolhas linguísticas indicam/apontam o posicionamento do falante diante do fato; observe-se, ainda, que algumas realizações linguísticas são mais ideológicas do que outras, ou mais irônicas do que outra. Isso se dá por meio de construções atributivas (candidata-rolha, "candidata ideal", virtual candidata, ministra-tampão). Essas mudanças nos papeis sociais atribuidos ao ator indicam que as identidades são designadas socialmente, se constituem e variam conforme o contexto sócio-cultural.

Segundo Da Silva (2009: 82), a classificação é um processo central na vida social, pois pode ser entendida como ato de significação pelo qual o mundo é ordenado e dividido em classes e grupos. Portanto, ao classificar Dilma Rousseff por meio de escolhas lexicais como candidata-rolha, "candidata ideal", "candidata de Lula", virtual candidata, ministra-tampão, os jornalistas marcam relações de poder, atribuindo valores negativos, depreciativos sobre sua conduta, competência e habilidades tanto políticas quanto administrativas. Ao dizer, ou classificar o que Dilma Rousseff é, deixa pressuposto que outros não o são e, ao fazê-lo, são demarcadas fronteiras políticas.

\subsection{Impersonalização por Objetivação}

Outra ocorrência encontrada no corpus é a objetivação. Nesse caso, Dilma Rouseff é representada por meio de referência ao local de trabalho, por meio de uma realização metonímica. Assis (2009) propõe uma forma de objetivação dos atores sociais que não foi contemplada por van Leeuwen: a Institucionalização. Segundo Assis, é a forma de referência ao ator social por meio da instituição a qual ele pertence. A Institucionalização também pode ser compreendida como forma de personificação/humanização das instituições, ou seja, a atribuição de características humanas a instituições, que, por si só, não podem agir no mundo. 
Nos exemplos 65 a 67, observa-se que o uso da objetivação não especifica o ator responsável pelas ações passíveis de acusação relatadas pelas matérias jornalísticas, ao contrário, exclui-o, ofuscando-o. A Casa Civil torna-se o participante da ação:

65) Ninguém duvida que a Casa Civil tenha armazenado munição suficiente para contraatacar PSDB e DEM no Congresso (Veja, 2008).

66) A Casa Civil afirma que é o Gabinete de Segurança Institucional, responsável pela segurança do presidente da República, que detém a palavra final sobre essa documentação (IstoÉ, 2007).

Outro subsistema da objetivação é a Somatização, cuja característica é a representação do ator social pelas partes do corpo. Dilma-ministra-précandidata também é assim representada pela mídia, principalmente nas matérias que tratam da transformação estética pela qual passou no ano 2008, em função da disputa eleitoral de 2010. Assim, a participante é dominada pelo corpo, em que um caráter de alienação é acrescentado:

67) Os cabelos, outrora curtos e castanho-escuros, ganharam um tom avermelhado mais claro e uma ligeira franja que esconde parte da testa. O resultado final pode ser resumido em uma palavra: suavidade (Veja, 2008).

68) O câncer no palanque. O governo tenta transformar um assunto grave e delicado, a doença da ministra Dilma Rousseff, em trunfo para a campanha presidencial do próximo ano (Veja, 2009).

Em 67, Dilma é representada por meio de algumas referências relativas a algumas partes de seu corpo. Em 68, por exemplo, na expressão "câncer no palanque", ocorre a somatização, uma forma de representar Dilma por meio de uma referência à doença desenvolvida no corpo. O uso dessa representação coloca em destaque a doença, acrescentando-lhe conotações político-ideológicas irônicas.

\section{CONSIDERAÇÕES FINAIS}

A maioria dos estudos atuais sobre o movimento das mulheres engendra o discurso da transformação sociocultural que, em vez de se pautar na imagem da mulher-para-o-outro, desloca-se para a mulher-para-ela-mesma; da mulher como agente de sua própria história, imagem de mulher-sujeito 
(Touraine, 2007). Estudos discursivos apontam para representações mais ativas e dinâmicas para as mulheres que ocupam cargos de poder (Morais, 2008; Assumpção, 2008).

As reflexões desenvolvidas neste estudo se coadunam com pesquisas que tratam de mulheres em cargos de poder, pois mostram que a representação de Dilma Rousseff, operada pelas mídias analisadas, engendra uma representação de sujeito-político-mulher, uma construção identitária pejorativa, estereotipada e deslegitimada.

Dilma Rousseff é mais personalizada do que impersonalizada nos dados, destacando-a por meio de nomes próprios, pronomes pessoais, dando visibilidade à participante na esfera público-política. No entanto, a realização da Personalização, por meio de escolhas léxico-gramaticais, caracteriza-se como um tipo de estratégia de depreciação, inclusive, irônicas. Algumas formas de representação dão à participante representada um caráter de alienação, de dominação, como é o caso da somatização: o foco no corpo focaliza a representação de Dilma Rousseff como objeto, como algo a ser produzido, alienado.

A participante é representada recorrentemente no corpus por meio de Funcionalização, Nomeaşão e Classificação. As duas primeiras são formas de atribuição de poder aos representados, seja pela valorização do papel desempenhado na sociedade, seja pela atribuição de identidades únicas; já a classificação, na maioria dos exemplos, rotula a participante de forma negativa, depreciativa e irônica.

Ainda vale ressaltar que, vinculada a algumas formas de representação, as construções avaliativas, atributivas, por meio de realizações lexicais, exprimem conteúdos interpessoais, mais que as experienciais, por meio de modificadores atitudinais bastante negativos. Muitas construções avaliativas estão relacionadas ao julgamento moral ou de competência administrativa e política de Dilma Rousseff.

As representações sociais encontradas sinalizam que as mídias analisadas, de alguma forma, tentam mostrar ao eleitor/leitor/observador que a ministra Dilma Rousseff está aceitando o jogo político do partido e, ainda, o jogo de marketing político, que objetiva torná-la um joguete do Presidente Lula: alguém que não conquistará um cargo, mas será colocada pela competência e popularidade de Lula. Ao representar Dilma como um tipo 
de candidato-produto, produzido por Lula e sua equipe, a mídia sinaliza que esse candidato deverá, então, conquistar um eleitorado-mercado e provocar nele votos-compra.

Recebido em março de 2011

Aprovado em junho de 2011

E-mails:1barbara@uol.com.br mcgomes@ufv.com.br

\section{REFERÊNCIAS BIBLIOGRÁFICAS}

Assumpção, M. A representação da mulher que trabalha na mídia brasileiras e americanas. Dissertação (Mestrado em Linguística Aplicada e Estudos da Linguagem) - Pontificia Universidade Católica de São Paulo, São Paulo, 2008.

Beltrão, L. 1976. Jornalismo Interpretativo. Porto Alegre, Sulina.

Da Silva, Tomaz Tadeu; Hall, Stuart; Woodward, Kathryn. 2009. Identidade e Diferença. A perspective dos Estudos Culturais. 9ed. Petrópolis: Vozes.

Fairclough, Norman. 2001. Discurso e Mudança Social. Tradução (org) Izabel Magalhães. Brasília: UNB.

2003. Analysing discourse: textual analysis for social research. London: Routledge.

Halliday, M.A.K. 1994. An introduction to functional grammar. London: Edward Arnold.

Halliday, M.A. K. 2004. An introduction to functional grammar. 3rd ed. Revised by Christian M. I. M. Mathiessen. London: Arnold Edition.

MeLo, José Marques de (Org.). 1992. Gêneros jornalísticos na Folha de S. Paulo. São Paulo: FTD.

MorAIs, F.B.C. 2008. Mulberes da política brasileira: um estudo sob a perspectiva sistêmico-funcional. Dissertação (Mestrado em Linguistica Aplicada e Estudos da Linguagem) - Pontifícia Universidade Católica de São Paulo, São Paulo.

Resende, V; Ramalho, V. 2006. Análise de discurso crítica. São Paulo: Contexto.

Sodré, M. 2006. As estratégias sensíveis: afeto, mídia e política. Rio de Janeiro: Vozes. 
Swain, T.N. 2004. Feminismo, corpo e sexualidade. In: Rial, C.S.M.; Toneli, M.J.F. Genealogias do silêncio: feminismo e gênero. Florianópolis: Editora Mulheres. p.180-197.

Touraine, A. O mundo das mulheres. Rio de Janeiro: Vozes, 2006.

van LeEuven, Theo.1996. The representation of social actors. In: CaldasCoulthard, C.R.; Coulthard, M. (Eds.). Texts and practices: readings in Critical Discourse Analysis. London: Routledge. p. 32-70.

van Leeuwen, Theo. 1997. A representação dos atores sociais. In: Pedro, Emilia Ribeiro. Análise Crítica do Discurso. Lisboa: Editora Caminho.

van Leeuwen, Theo. 2008. Discourse and Practice: New Tools for Critical Discourse Analysis (Oxford Studies in Sociolinguistics). London: Paperback. 